(C) 2019. This manuscript version is made available under the CCBY-NC-ND 4.o license http://creativecommons.org/licenses/by-nc-nd/4.o/ 


\section{Accepted Manuscript}

High temperature corrosion behaviour on molten nitrate salt-based nanofluids for CSP plants

Angel G. Fernández, Belen Muñoz-Sánchez, Javier Nieto-Maestre, Ana García-

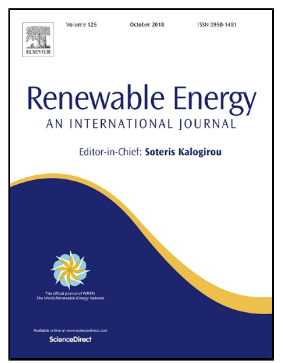

Romero

PII:

S0960-1481(18)30803-6

DOI:

10.1016/j.renene.2018.07.018

Reference:

RENE 10292

To appear in:

Renewable Energy

Received Date:

08 February 2018

Accepted Date:

03 July 2018

Please cite this article as: Angel G. Fernández, Belen Muñoz-Sánchez, Javier Nieto-Maestre, Ana García-Romero, High temperature corrosion behaviour on molten nitrate salt-based nanofluids for CSP plants, Renewable Energy (2018), doi: 10.1016/j.renene.2018.07.018

This is a PDF file of an unedited manuscript that has been accepted for publication. As a service to our customers we are providing this early version of the manuscript. The manuscript will undergo copyediting, typesetting, and review of the resulting proof before it is published in its final form. Please note that during the production process errors may be discovered which could affect the content, and all legal disclaimers that apply to the journal pertain. 


\title{
High temperature corrosion behaviour on molten nitrate salt-based nanofluids for CSP plants
}

\author{
Angel G. Fernández ${ }^{1 *}$, Belen Muñoz-Sánchez ${ }^{2,3}$, Javier Nieto-Maestre ${ }^{3}$, Ana García- \\ Romero $^{2}$ \\ ${ }^{1}$ Energy Development Center. University of Antofagasta. Avenida Universidad de Antofagasta \\ 02800, Antofagasta, Chile. \\ ${ }^{2}$ Department of Mining Engineering, Metallurgy and Materials Science, University of the \\ Basque Country (UPV/EHU), Rafael Moreno "Pitxitxi”, 2. 48013 - Bilbao (Vizcaya). Spain. \\ ${ }^{3}$ Tecnalia Research and Innovation, Mikeletegi Pasealekua, 2. 20009 - San Sebastián \\ (Guipúzcoa). Spain.
}

*Corresponding author E-Mail: angel.fernandez@uantof.cl

\section{Abstract}

Recently, a number of theoretical and experimental studies have been performed to understand the effect of nanoparticles on thermal properties and heat transfer performance but there is a lack regarding their corrosion properties. In this work, an extended corrosion characterization (at central tower plant storage temperature $\left.\left(565^{\circ} \mathrm{C}\right)\right)$ has been carried out in two different grades of solar salt (industrial and refined purity) doped with the addition of $1 \mathrm{wt} \% \mathrm{Al}_{2} \mathrm{O}_{3}$ nanoparticles or $1 \mathrm{wt} \% \mathrm{SiO}_{2}$ nanoparticles. Corrosion rates were determined in commercial stainless steel commonly used in CSP technology (347SS) by gravimetric tests, measuring the weight gain during 1000 hours, identifying the corrosion products by Scanning Electron Microscopy (SEM) and X-Ray Diffraction (XRD). The lowest corrosion rate $(0.007 \mathrm{~mm} /$ year $)$ was obtained in the refined solar salt with the addition of $1 \mathrm{wt} \% \mathrm{Al}_{2} \mathrm{O}_{3}$ nanoparticles. A protective layer was formed in the steel-salt interphase, identified through XRD as $\mathrm{Al}_{2} \mathrm{O}_{3}$.

Additionally, hematite $\left(\mathrm{Fe}_{2} \mathrm{O}_{3}\right)$ and magnetite $\left(\mathrm{Fe}_{3} \mathrm{O}_{4}\right)$ were obtained as unprotective corrosion products throughout the test carried out with or without nanoparticles. In addition, the presence of impurities on the salts generated some stable compounds, as magnesium ferrite $\left(\mathrm{MgFe}_{2} \mathrm{O}_{4}\right)$.

Keywords: Nanoparticles; molten salts; corrosion; Concentrated Solar Power 
List of nomenclatures:

CSP: Concentrated Solar Power

SEM: Scanning Electron Microscopy

XRD: X-ray diffraction

TES: Thermal Energy Storage

LCOE: Levelized Cost of Electricity

RSS: Refined Solar Salt

ISS: Industrial Solar Salt

ANP: Alumina Nanoparticle

SiNP: Silica Nanoparticle

EDX: Energy Dispersive X-Ray

\section{Introduction}

Concentrating Solar Power (CSP) technology captures and stores the sun's energy in the form of heat, using materials that are low cost and stable for decades. Today's most advanced CSP systems are towers integrated with two-tank molten-salt TES, delivering thermal energy at $565{ }^{\circ} \mathrm{C}$ for integration with conventional steam-Rankine power cycles [1]. This design has lowered the cost of CSP electricity by approximately $50 \%$ over the prior generation of parabolic trough systems. However, the decrease in cost of CSP technologies has not kept pace with the falling cost of solar photovoltaic systems and further research is needed. High-temperature molten salt has been commonly used as an effective working fluid for CSP systems, increasing electrical efficiency and reducing the Levelized Cost of Electricity (LCOE). However, the high freezing point of the Solar Salt $\left(221^{\circ} \mathrm{C}\right)$ may result in its solidification on a cloudy day or at night. In this direction, the design of multicomponent mixtures by the addition of alkali/alkaline earth nitrates could extend the working temperature range of thermal energy storage $[2,3]$ but an enhancement in the thermal conductivity and heat capacity at storage temperatures must be necessary for a successful development of this technology.

In this direction, high temperature nanofluids have received great attention over the last decade due to their increased specific heat compared to the base fluids $[4,5]$. In the last years, several researches have been performed to understand the effect of nanoparticles on thermal properties and heat transfer performance [6-10]. These researches have been focused on Thermal Energy Storage (TES) materials (molten salts) commonly used in 
Concentrated Solar Power (CSP) plants and a majority of the works [10-12] showed that the specific heat of nano-salt was increased. The percentage of addition (used in this work, $1 w t . \%)$ is based on the excellent thermal transfer obtained by several authors with the same nanofluids [5]. Many efforts have been required to carry out the research work published up to date due to the lack of standards for the preparation, the measurement and the evaluation of the results, as well as to approach the understanding of the behaviour of the composite at the nano-scale [13]. Therefore, the fact of having the nanoparticles welldispersed rather than agglomerated is one of the objective in this technology since it will cause fluidity issues or higher corrosion behavior. Well-dispersed nanoparticles essentially result in an increased surface to volume ratio, which can lead to enhanced thermal conductivity, a transport-related property. Jo et al.[4] conclude that a compressed liquid creates a layer adjacent to the interface with the solid and the specific heat capacity enhancement in a nanomaterial can result from an increased interface area between the surrounding liquid and the nanoparticles improving the specific heat capacity of nanomaterials.

Different authors [14-17] have evaluated the effect of the impurities in the convencional molten salts proposed as thermal energy storage material concluding that impurities tend to drive corrosion. However, there is not information in the literature regarding the corrosive effect in molten salt based nanofluids. The corrosive evaluation of these improved molten salts must be studied since nanoparticles are solid in the mixture, being potential candidates to promote erosion/corrosion in CSP pipelines.

This is one of the main factors to take into account in the corrosion test performed during 1000 hours. The aim of this paper is the corrosive evaluation of two grades of solar salt (SQM, Refined (RSS) and Industrial (ISS) grades) with the most common addition of $\mathrm{Al}_{2} \mathrm{O}_{3}$ and $\mathrm{SiO}_{2}$ nanoparticles found in the literature (1wt.\%), at $565^{\circ} \mathrm{C}$ in contact with $347 \mathrm{SS}$.

\section{Materials and methods}

The saline nitrates used in the research were $\mathrm{NaNO}_{3}$ and $\mathrm{KNO}_{3}(\mathrm{SQM}$ grades RSS and ISS). Two Solar Salts (60:40 wt. of $\left.\mathrm{NaNO}_{3}: \mathrm{KNO}_{3}\right)$ of different purity were prepared: the refined grade, RSS (SQM, $\mathrm{NaNO}_{3} \geq 99.5$ wt.\%; SQM, $\mathrm{KNO}_{3} \geq 99.6$ wt.\%) and the industrial grade, ISS (SQM, $\mathrm{NaNO}_{3} \geq 98.0$ wt.\%; SQM, $\mathrm{KNO}_{3} \geq 95.0$ wt.\%). Two types of ceramic nanoparticles were selected, $\mathrm{Al}_{2} \mathrm{O}_{3}$ nanoparticles 
98 (ANPs) and $\mathrm{SiO}_{2}$ nanoparticles (SiNPs). ANPs were purchased from Kawaken 99 Chemicals as an industrial water-based nanofluid, Alumisol 10A, containing fiber100 shaped boehmite nanoparticles ( $\mathrm{L}=50 \mathrm{~nm}, \phi=10 \mathrm{~nm}$ ) at $10 \mathrm{wt} \%$ according to the

101

102

103

104

105

106

107

108

109

110

111

112

113

114

115

116

117

118

119

120

121 manufacturer. The boehmite (aluminium oxyhydroxide, $\mathrm{AlOOH}$ ) is a precursor of the $\gamma-\mathrm{Al}_{2} \mathrm{O}_{3}$. On the other side, a dispersion of colloidal silica at $30 \mathrm{wt} \%$, Ludox SM30, from Sigma-Aldrich was used as a source of spherical SiNPs.

Four nanofluids were produced with these materials, including 1 wt.\% of each nanoparticle in combination with each of the salts RSS and ISS. Once the synthesis process involving nanoparticles addition was arranged (addition procedure was explained in a previous paper [18]), the mixed formulations were sealed inside a dry box with desiccants. The steel analyzed in the saline medium was an austenitic stainless steel $(347 \mathrm{SS}, 2 \% \mathrm{Mn} / 11 \% \mathrm{Ni} / 18 \% \mathrm{Cr}$ ) commonly proposed as container material in CSP plants.

The dimensions of the steel samples used in the gravimetric corrosion tests were 20 $\mathrm{mm} \times 10 \mathrm{~mm} \times 2 \mathrm{~mm}$. A grinding process was performed using silicon carbide ( $\mathrm{SiC})$ P1000 abrasive paper with a (SiC grit size: $18.3 \mu \mathrm{m})$. This treatment produces a homogeneous surface in the sample and promotes delamination of the possible oxides and the small imperfections where corrosion could be located. The samples were subsequently washed with acetone in an ultrasound bath to eliminate any remaining dirt. The dimensions of each sample were measured using an electronic caliber $( \pm 0.01 \mathrm{mg})$, and each sample was weighed using an analytical balance (Mettler Toledo) with a $0.00001 \mathrm{~g}$ responsiveness. Subsequently, the samples were placed into alumina crucibles (Fig 1) with the saline mixture and then heated in a resistance furnace at $565^{\circ} \mathrm{C}$. 


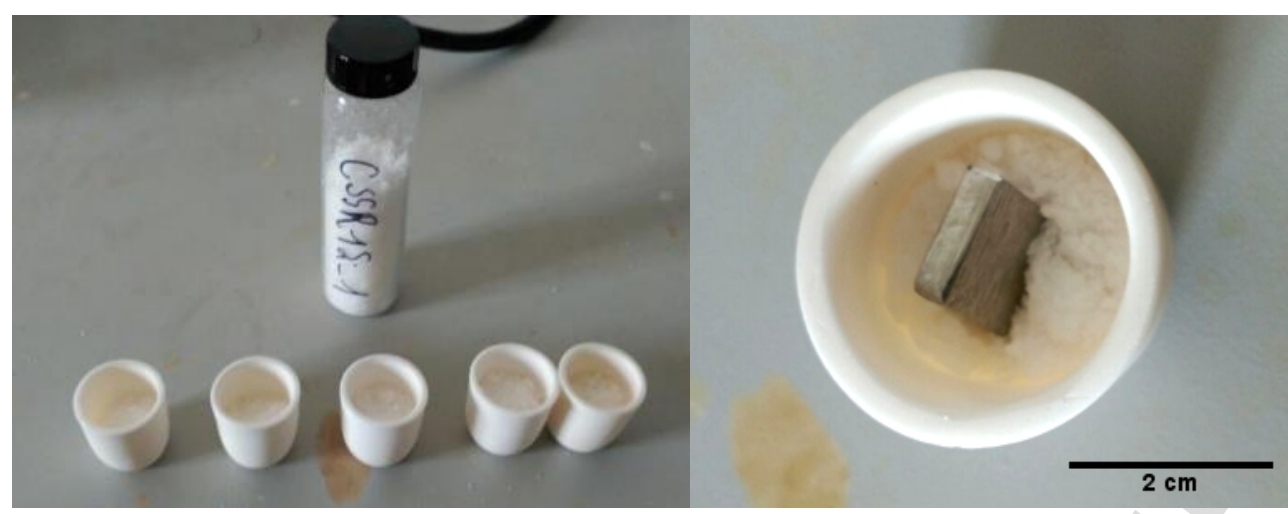

Figure 1. Alumina crucibles filled in with nanofluid (left) and alloy specimen immersed into the solid nanodoped-salt before the test (right).

Table 1: Impurity content in solar salts employed in this work

\begin{tabular}{|c|c|c|}
\hline Impurity & RSS Solar Salt (wt\%) & ISS Solar Salt (wt\%) \\
\hline Chloride & 0.060 & 0.260 \\
\hline Perchlorate & 0.064 & 0.247 \\
\hline Sulfate & 0.011 & 0.146 \\
\hline Carbonate & 0.010 & 0.009 \\
\hline Nitrite & $<0.001$ & $<0.001$ \\
\hline
\end{tabular}

Different technical grades of solar salt (refined and industrial) have been selected for the nanoparticles addition since the impurities present in the salt could have influence in the integration of these particles in the salt matrix. Static gravimetric measurements were performed after 200, 400, 600, 800 and 1000 hours of exposure at the testing temperature in the isothermal immersion test. After the samples were removed from the crucible, they were left to cool down slowly and subsequently washed out with warm distilled water to eliminate the salt in which they were immersed and they were dried and weighed. Five weight measurements were taken from each sample and between each measurement the samples were kept into dry box with desiccants. The average value of the weight obtained from the five measurements has been used for the analysis of the results. The formula (Eq. 1) to calculate the mass gain over time is:

$$
\frac{\Delta \mathrm{m}}{S_{0}}=\frac{m_{f}-m_{i}}{S_{0}}
$$


141 where $\mathrm{m}_{\mathrm{i}}$ is the initial mass of the specimen, $\mathrm{m}_{\mathrm{f}}$ is the mass of the same at time $\mathrm{t}$ and

$142 \mathrm{~S}_{0}$ is the initial area of the specimen. Finally, the microstructural characterization

143 has been carried out in a scanning electron microsopy (SEM, JEOL 6460LV with

144 EDAX)), using EDS analysis in order to stablish the morphology as well as the

145 corrosion mechanism. X-ray diffraction analysis (with a grazing angle of $0.5^{\circ}$ )

146 model X'Pert Pro/MRD from Panalytical was used for the corrosion components

147 elucidation after 1000 hours of test.

3. Results

3.1. Corrosion of ISS and its nanofluids

150 The gravimetric weight gain that occurs on ISS is shown in figure 2, where the results

151 obtained with the industrial grade solar salt (ISS) and its corresponding nanofluids (the

152 ISS with $1 \% \mathrm{Al}_{2} \mathrm{O}_{3}$, and the ISS with $1 \% \mathrm{SiO}_{2}$ ) can be compared.

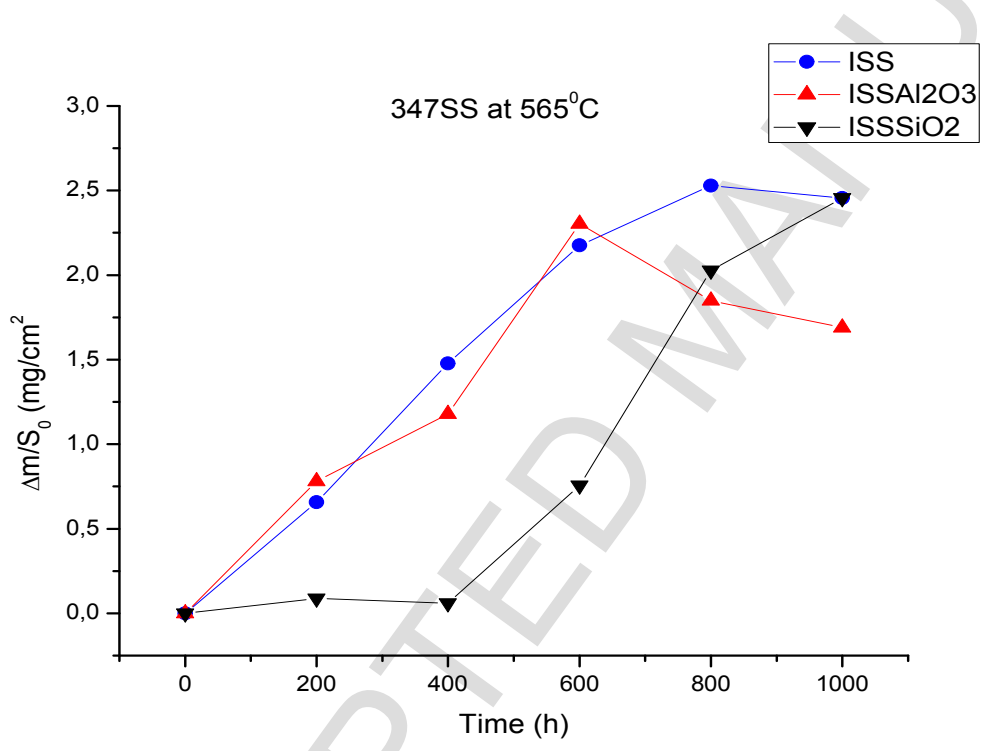

153

154 Figure 2: Gravimetric weight gain curve obtained in ISS and its nanofluids for $347 \mathrm{SS}$ at $565^{\circ} \mathrm{C}$

155 At 600 hours of experiment, the corrosion produced by ISS $+1 \% \mathrm{Al}_{2} \mathrm{O}_{3}$ was higher compared with the weight gain in the solar salt without nanoparticles. Beyond this point the corrosion rate is reduced, probably due to the sedimentation of the nanoparticles at the bottom of the crucible.

159 To explain this behavior, a micro-structural (surface and cross section) study of the SS347 160 was performed using scanning electron microscopy (SEM). Figure 3 shows the sample surface morphology of the steel after 800 hours of exposure to ISS $+1 \% \mathrm{wt}$. $\mathrm{Al}_{2} \mathrm{O}_{3}$, as well as an analysis via Energy-Dispersive X-ray spectroscopy (EDX) of the particles 
163 found on the surface. At the end of the test, a uniform sodium ferrite $\left(\mathrm{Na}_{2} \mathrm{FeO}_{4}\right)$ scale was 164 obtained.

\begin{tabular}{|l|c|c|c|}
\hline Spectrum & O & Na & Fe \\
\hline Spectrum 1 & 40.28 & 32.59 & 27.13 \\
\hline Spectrum 2 & 38.99 & 20.21 & 40.80 \\
\hline
\end{tabular}

165

166

167

168

169

170

171

172

173

174

175

176

177

178

179

180

181

182

183

184

185

186

187

188

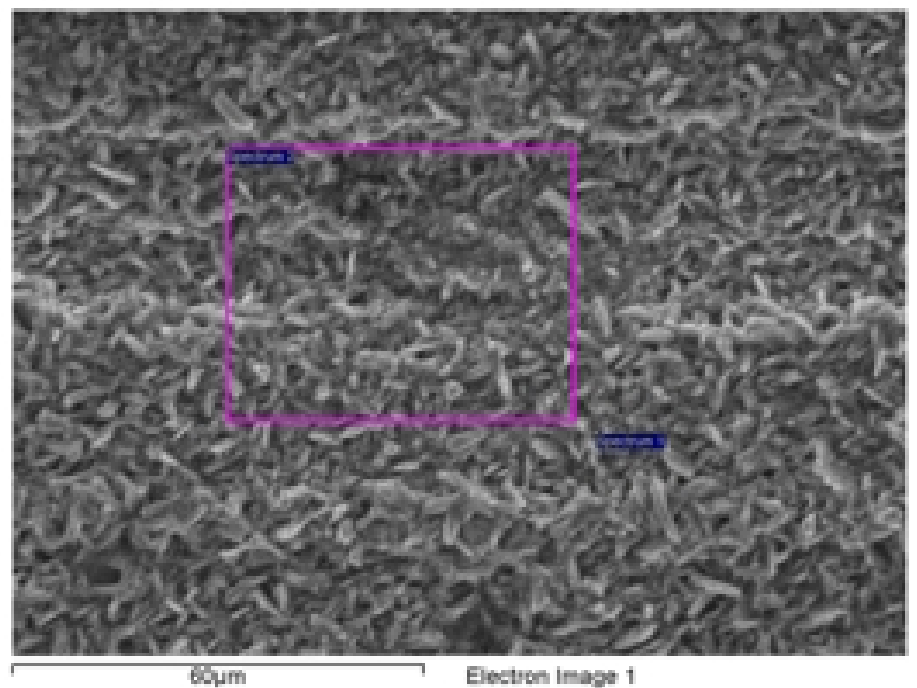

Figure 3: Detail of the 347SS specimen surface after 800 hours immersed into ISS $+1 \% \mathrm{Al}_{2} \mathrm{O}_{3}$

For the cross sectional study, SEM pictures have been obtained by backscattered electron microscopy.

\begin{tabular}{|l|c|c|c|c|c|c|c|c|c|}
\hline Spectrum & $\mathbf{O}$ & $\mathbf{N a}$ & $\mathbf{S i}$ & $\boldsymbol{K}$ & $\mathbf{C a}$ & $\mathbf{C r}$ & $\mathbf{M n}$ & $\mathbf{F e}$ & $\mathbf{N i}$ \\
\hline Spectrum 1 & 38.58 & 7.39 & - & - & 0.26 & 0.77 & 1.36 & 51.64 & - \\
\hline Spectrum 2 & 33.20 & 1.24 & - & 0.23 & - & 2.05 & 1.42 & 61.40 & 0.47 \\
\hline Spectrum 3 & 28.72 & 1.49 & 0.80 & 0.26 & - & 4.40 & 1.71 & 61.74 & 0.88 \\
\hline Spectrum 4 & 19.85 & 0.72 & 1.02 & - & - & 28.00 & 1.59 & 38.64 & 10.19 \\
\hline Spectrum 5 & 14.83 & & 0.71 & - & - & 20.06 & 1.35 & 46.82 & 16.23 \\
\hline
\end{tabular}

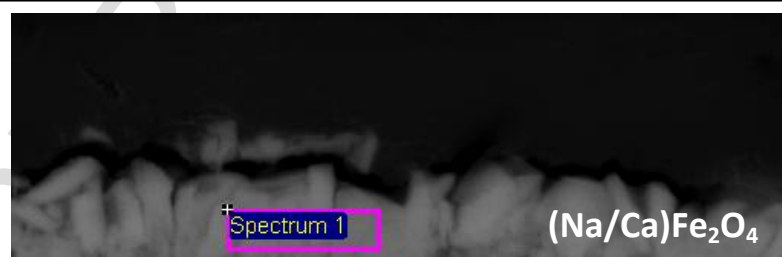

$\mathrm{Ni}-\mathrm{Cr}-\mathrm{O}$

Spectrum 3

'Spectrum 4

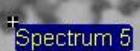


189

190

191

192

193

194

195

196

197

198

199

200

201

202

203

204

205

206

207

208

209

210

211

212

213

214

A protective layer composed by $\mathrm{Ni}-\mathrm{Cr}-\mathrm{O}$ has been detected in the steel surface and in the upper part an non protective layer composed by $(\mathrm{Na} / \mathrm{Ca}) \mathrm{Fe}_{2} \mathrm{O}_{4}$ was obtained, trough the following reactions:

$$
\begin{array}{ll}
\mathrm{Na}_{2} \mathrm{O}+\mathrm{Fe}_{2} \mathrm{O}_{3} \rightarrow \mathrm{Na}_{2} \mathrm{Fe}_{2} \mathrm{O}_{4} & \text { (Reac. 1) } \\
\mathrm{CaO}+\mathrm{Fe}_{2} \mathrm{O}_{3} \rightarrow \mathrm{CaFe}_{2} \mathrm{O}_{4} & \text { (React. 2) }
\end{array}
$$

On the other hand, for ISS +1 wt. $\% \mathrm{SiO}_{2}$, the analysis of the surface shown in figure 5 presents a less compact corrosion layer, probably due to the Si content detected in the corrosion layer. This influence of the Si presence in corrosion layers was recently publish by Hamid et al. [19], concluding that $1 \mathrm{wt} \% \mathrm{Si}$ additions could modify the steel surface interacting with the impurities present in the corrosive environment along with the alloying elements of the steel.

\begin{tabular}{|l|c|c|c|c|c|}
\hline Spectrum & $\boldsymbol{O}$ & $\mathbf{N a}$ & $\mathbf{M g}$ & $\mathbf{S i}$ & $\mathbf{C a}$ \\
\hline Spectrum 1 & 64.69 & 35.31 & - & - & - \\
\hline Spectrum 2 & 64.29 & 8.15 & - & - & 27.56 \\
\hline Spectrum 3 & 45.89 & 27.72 & 9.12 & 17.27 & - \\
\hline
\end{tabular}

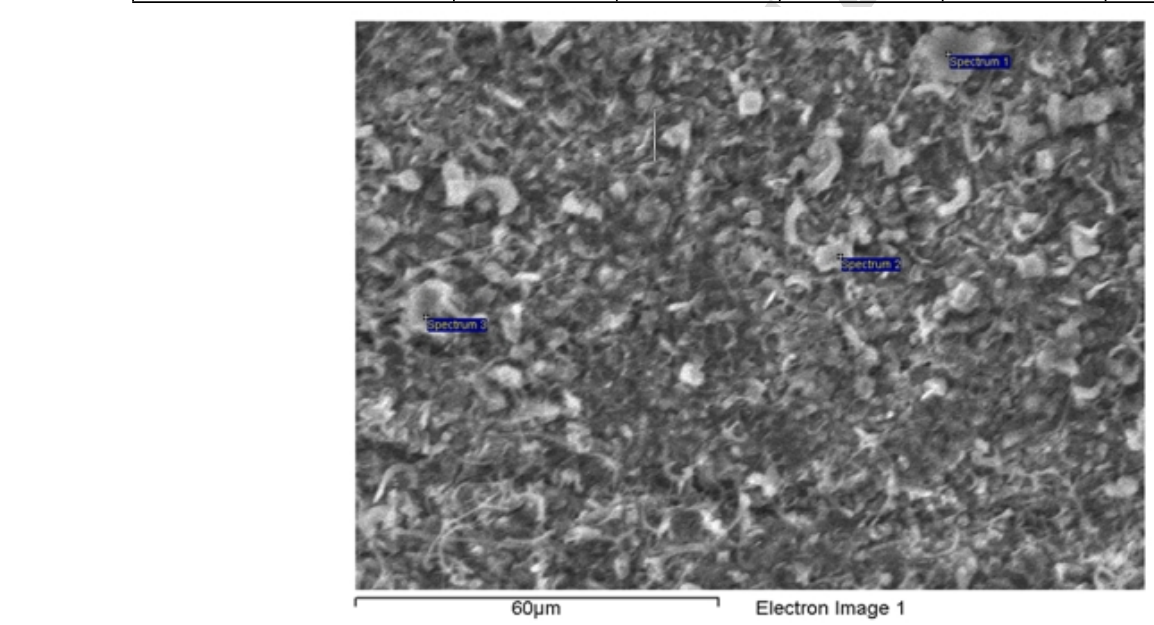

Figure 5: Superficial image of 347SS immersed during 800 hours in ISS +1 wt. $\% \mathrm{SiO}_{2}$

This silicon content was also detected in the cross sectional study at different levels through the corrosion layer. The composition of these products have been determined by XRD (table 2) and in this case, $\mathrm{SiO}_{2}$ and $\mathrm{Fe}_{2} \mathrm{SiO}_{4}$ were identified in the steel and in the remaining salt after the corrosion test. 


\begin{tabular}{|l|c|c|c|c|c|c|c|c|c|c|}
\hline Spectrum & $\mathbf{O}$ & $\mathbf{N a}$ & $\mathbf{M g}$ & $\mathbf{S i}$ & $\boldsymbol{K}$ & $\mathbf{C a}$ & $\mathbf{C r}$ & $\mathbf{M n}$ & $\mathbf{F e}$ & $\mathbf{N i}$ \\
\hline Spectrum 1 & 50.96 & & & & & 47.81 & & & 1.23 & \\
\hline Spectrum 2 & 32.71 & 0.94 & 0.41 & 0.42 & & & 8.27 & 1.62 & 52.67 & 2.96 \\
\hline Spectrum 3 & 35.32 & 2.08 & 1.61 & 0.42 & & 7.45 & 3.50 & 1.52 & 36.80 & 11.29 \\
\hline Spectrum 4 & 35.15 & 4.66 & 3.54 & & 0.34 & & 0.59 & 1.02 & 54.70 & \\
\hline Spectrum 5 & 18.45 & & 0.84 & 0.67 & & 0.29 & 16.75 & 1.80 & 52.55 & 8.65 \\
\hline Spectrum 6 & & & & 0.42 & & & 13.90 & 1.14 & 72.62 & 11.91 \\
\hline
\end{tabular}

Figure 6: Cross sectional image of 347SS immersed during 1000 hours in ISS $+1 \mathrm{wt} . \% \mathrm{SiO}_{2}$.

A non protective layer composed by $(\mathrm{Na}-\mathrm{Ca}-\mathrm{Mg}) \mathrm{Fe}_{2} \mathrm{O}_{4}$ has been formed in the corrosion layer, responsible of the higher gravimetric weight gain determined when the steel is immersed into ISS $+1 \mathrm{wt} . \% \mathrm{SiO}_{2}$ as shown in figure 1.

It is important to highlight that the stability of the salts during the corrosion process showed an important reduction when $\mathrm{SiO}_{2}$ nanoparticles are involved and the salt solidified two times during the corrosion test.

Yang et al. [20] reported that when molten nitrate salts come into contact with a containment substrate such as quartz or stainless steel at temperatures above $500^{\circ} \mathrm{C}$, the release of nitrogen oxide could be foreseen due to the extensive reaction of $\mathrm{NO}_{3}{ }^{-}$with $\mathrm{SiO}_{2}$ or with $\mathrm{Cr}$, respectively. The reactions included:

The results attained in our work revealed that the presence of the $\mathrm{SiO}_{2}$ nanoparticles promotes the decomposition of nitrate or nitrite to form silicates $\left(\mathrm{Na}_{2} \mathrm{SiO}_{3}\right)$ and $\mathrm{NO}$ gas. 
241 In order to compare the corrosion behavior produced by a Solar Salt with a different

242

243

244

245

246

247

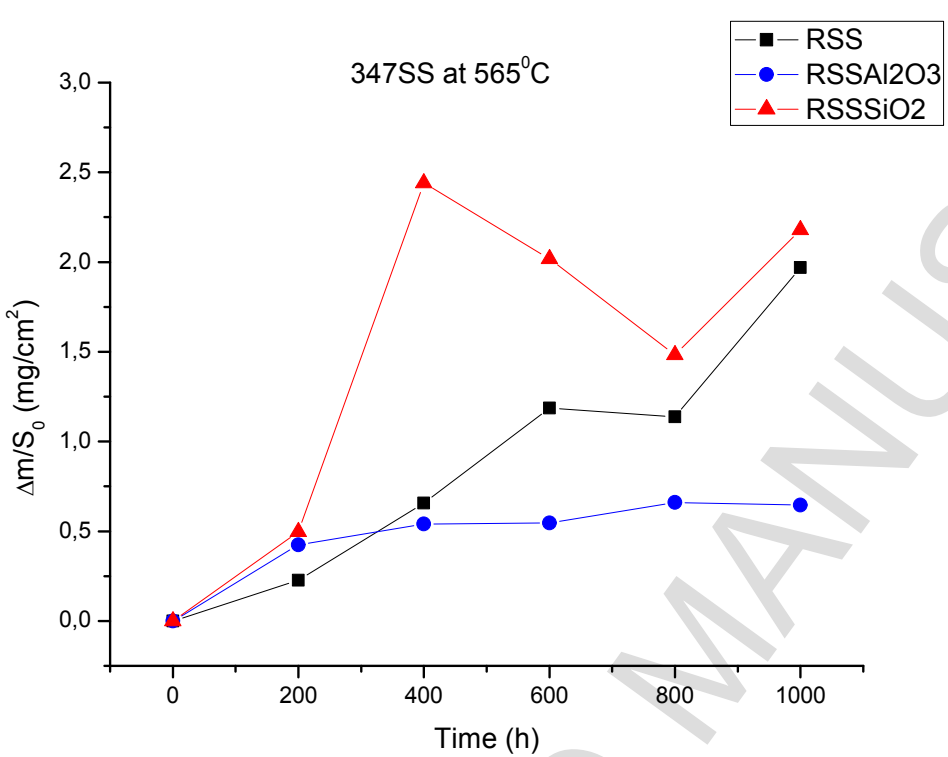
wt. $\% \mathrm{Al}_{2} \mathrm{O}_{3}$ showing a gravimetric weight gain around $0.5 \mathrm{mg} / \mathrm{cm}^{2}$.

7

248

249

250

251

252

253

254

255

256

257

258

259

260 impurity content (lower percentage of chloride), RSS provided by SQM has been studied. In this case, the gravimetric weight gain is lower compared to the previous case using ISS and there is not a clear correlation between the corrosion produced by the addition of nanoparticles to the RSS. The better corrosion behavior was obtained for RSS +1

Figure 7: Gravimetric weight gain of the 347SS specimens immersed into the refined solar salt (RSS) and the corresponding nanofluids at $565^{\circ} \mathrm{C}$

In this direction, it is important to highlight the morphology of the specimens surface immersed in $\mathrm{RSS}+1$ wt. $\% \mathrm{Al}_{2} \mathrm{O}_{3}$ (figure 7), showing needle-like structures containing $\mathrm{Al}$. This structure, integrated in the steel matrix, increase the protection against the corrosion produced by molten salts. 


\begin{tabular}{|l|c|c|c|c|c|c|c|c|}
\hline Spectrum & $\boldsymbol{C}$ & $\boldsymbol{O}$ & $\mathbf{N a}$ & $\mathbf{M g}$ & $\boldsymbol{C a}$ & $\boldsymbol{C r}$ & $\mathbf{M n}$ & $\boldsymbol{F e}$ \\
\hline Spectrum 1 & 12.84 & 40.40 & 5.98 & 1.73 & 4.49 & 1.14 & 0.89 & 32.53 \\
\hline Spectrum 2 & 9.89 & 33.31 & 9.59 & 1.59 & 3.07 & 1.13 & 3.34 & 38.09 \\
\hline Spectrum 3 & 7.99 & 36.09 & 4.93 & 2.85 & 4.80 & 1.18 & 2.08 & 40.08 \\
\hline
\end{tabular}

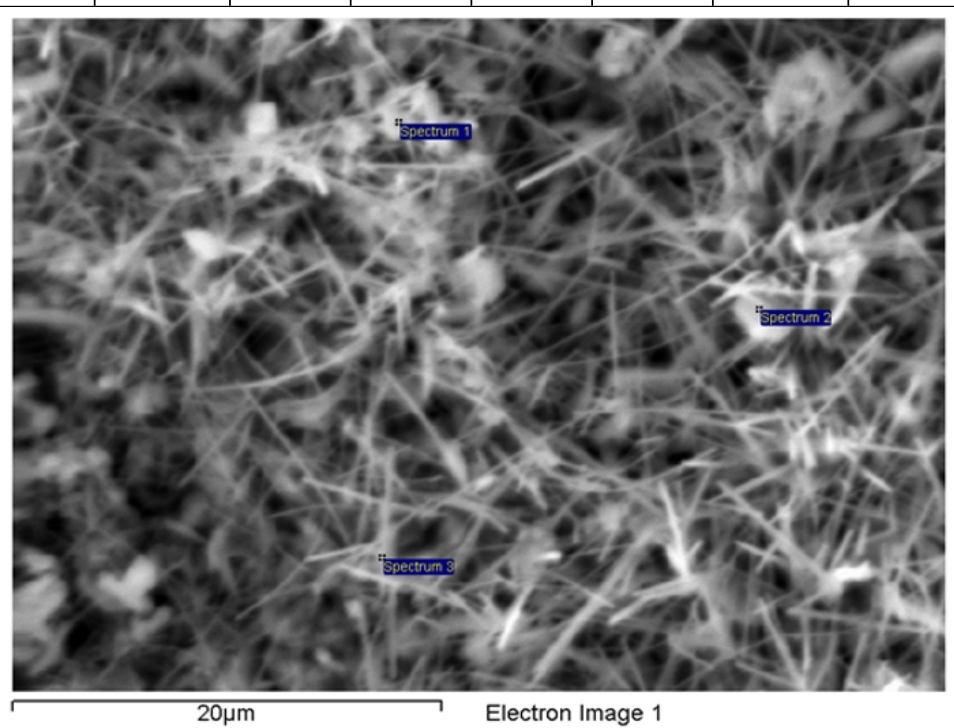

Figure 8: Detail of the surface morphology of a 347SS specimen immersed in $\mathrm{RSS}+1 \mathrm{wt} . \% \mathrm{Al}_{2} \mathrm{O}_{3}$ 264 for 800 hours.

265 Presently, there is no a clear explanation about the potential mechanism leading to the corrosion protection obtained by this needle-like aluminium oxide morphology. An extended research will be carried out in the future to understand the fundamentals behind the better corrosion behaviour due to the $\mathrm{Al}_{2} \mathrm{O}_{3}$ nanoparticles. On the other hand, the formation of this corrosion-protective layer could reduce the heat capacity enhancement produced in the molten salt by the addition of the nanoparticles, which was indeed the main objective pursued in their development $[11,18]$. If a synergic effect between the corrosion protection and the thermal properties could be attained, the key for an interesting increment of the efficiency and the cost reduction of this technology could have been found.

The alumina needles were also observed on the cross sections of the specimens, like that shown in figure 8. In this case a compact protective layer of spinel $\left(\mathrm{FeCr}_{2} \mathrm{O}_{4}\right)$ formed on

277 the steel surface, which leads to increase the corrosion resistance of the steel in contact with the molten salt. 


\begin{tabular}{|l|c|c|c|c|c|c|c|c|c|c|c|c|}
\hline Spectrum & $\boldsymbol{O}$ & $\mathbf{N a}$ & $\mathbf{M g}$ & $\boldsymbol{A l}$ & $\mathbf{S i}$ & $\boldsymbol{C l}$ & $\boldsymbol{K}$ & $\mathbf{C a}$ & $\boldsymbol{C r}$ & $\mathbf{M n}$ & $\boldsymbol{F e}$ & $\mathbf{N i}$ \\
\hline Spectrum 1 & 32.35 & 0.75 & 0.48 & & & & & 0.84 & 10.99 & 1.83 & 50.68 & 2.09 \\
\hline Spectrum 2 & 36.13 & 7.28 & 1.41 & 0.76 & & 0.32 & & 1.05 & 0.98 & 1.70 & 50.38 & \\
\hline Spectrum 3 & 32.76 & 0.59 & 0.58 & & 0.37 & & & 0.54 & 11.16 & 1.96 & 51.48 & 0.55 \\
\hline Spectrum 4 & 29.06 & & & & 0.81 & & 0.36 & & 29.69 & 2.22 & 34.50 & 3.36 \\
\hline
\end{tabular}

Figure 9: Detail of the $347 \mathrm{SS}$ specimen cross-section immersed into ISS $+1 \% \mathrm{Al}_{2} \mathrm{O}_{3}$ for 293 1000 hours

According to the obtained gravimetric curve (figure 7), the steel immersed in the refined solar salt containing $1 \mathrm{wt} . \% \mathrm{SiO}_{2}$, presents irregularities on the mass increment. This behavior could be explained due to the spallation of the oxidic layer, as can be observed on the surface morphology of the specimen shown in figure 10.

\begin{tabular}{|l|l|l|l|l|l|l|}
\hline Spectrum & $\mathbf{O}$ & $\mathbf{N a}$ & $\boldsymbol{K}$ & $\mathbf{C a}$ & $\mathbf{C r}$ & $\boldsymbol{F e}$ \\
\hline Spectrum 1 & 30.71 & 13.78 & - & - & 4.74 & 50.76 \\
\hline Spectrum 2 & 34.34 & 24.77 & 0.79 & 2.24 & - & 37.86 \\
\hline
\end{tabular}

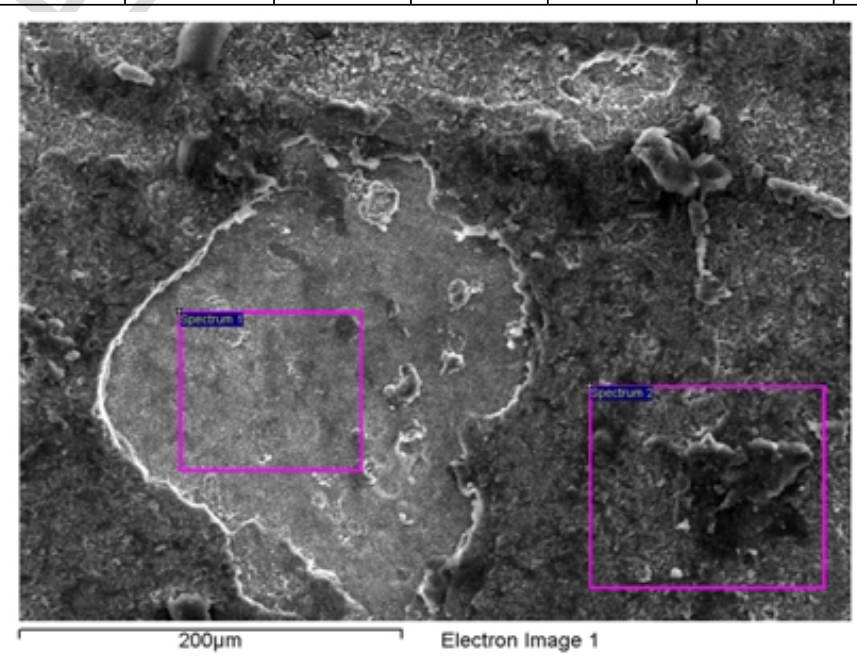


309

310

311

312

313

314

315

316

317

318

319

320

321

322

323

324

325

326

327

328

329

330

331

332

333

334

335

336

337

338

339

(1)

Figure 10: Detail of the 347SS specimen surface after immersed in RSS $+1 \mathrm{wt} . \% \mathrm{SiO}_{2}$ for 800 hours

The EDX analysis of the surface after the oxide-spallation was carried out (pink box on the left, in figure 10), as well as the analysis of the oxide surface adhered to the specimen (pink box on the right, in figure 10). The composition of the surface after spallation (spectrum 1) presents a higher $\mathrm{Cr}$ content.

This is a protective layer, which was seen in the cross section of the specimen (figure 11) in the inner zone, close to the steel surface. In this case the thickness of the corrosion layer obtained was 12.13 microns at the end of the test, showing the higher weight gain according the gravimetric curve (figure 7).

\begin{tabular}{|l|l|l|l|l|l|l|l|}
\hline Spectrum & $\mathbf{O}$ & $\mathbf{N a}$ & $\mathbf{S i}$ & $\mathbf{C r}$ & $\mathbf{M n}$ & $\mathbf{F e}$ & $\mathbf{N i}$ \\
\hline Spectrum 1 & 35.50 & 7.07 & 0.57 & 0.96 & 0.86 & 55.05 & - \\
\hline Spectrum 2 & 29.12 & - & 0.56 & 6.15 & 1.28 & 59.22 & 3.66 \\
\hline Spectrum 3 & 19.78 & - & 0.68 & 30.35 & 1.74 & 31.07 & 16.37 \\
\hline Spectrum 4 & 32.24 & - & 1.14 & 14.90 & 1.99 & 47.12 & 2.61 \\
\hline Spectrum 5 & 17.70 & - & 0.71 & 28.50 & & 35.72 & 17.37 \\
\hline
\end{tabular}

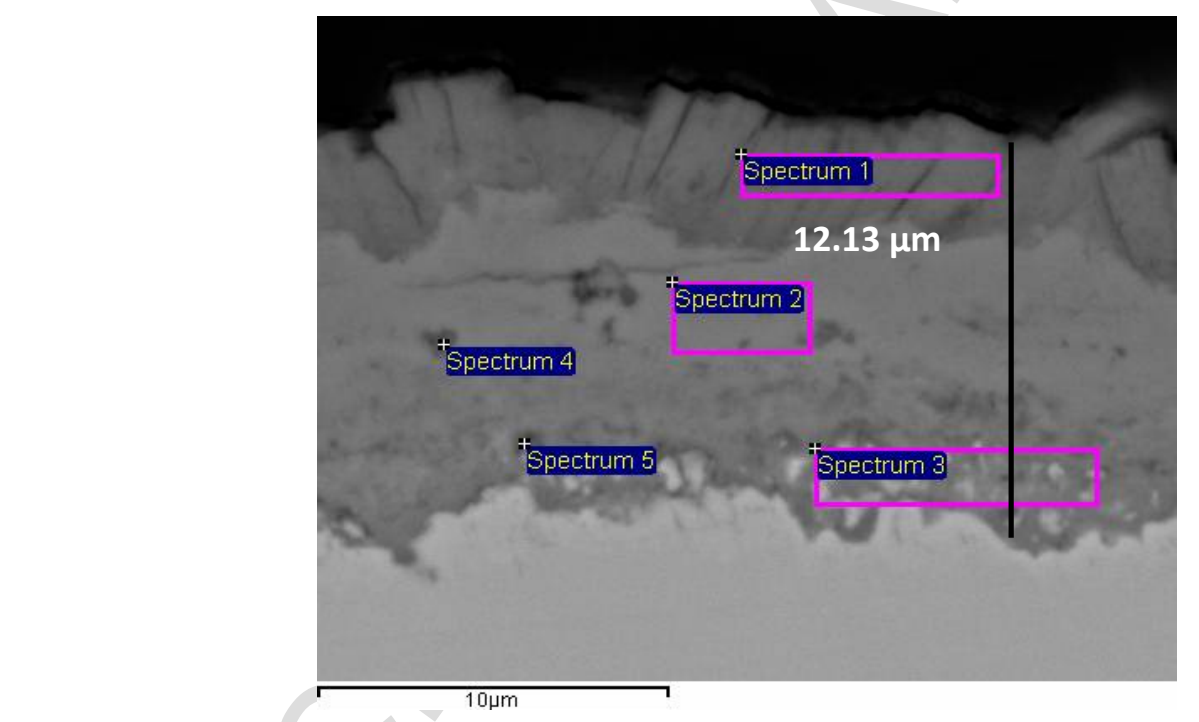

Figure 11: Detail of the 347SS specimen cross-section after immersed into ISS+1 wt. $\% \mathrm{SiO}_{2}$ for 1000 hours

XRD analysis were carried out after the corrosion test, both in the samples as well as in the salts in contact with them. Results are shown in table 2. 
Table 2: Corrosion products obtained by XRD in the steels tested and in the salt remaining

\begin{tabular}{|c|c|c|c|c|c|}
\hline \multirow{2}{*}{ Molten salts } & \multirow{2}{*}{$\begin{array}{c}\text { Nano } \\
\text { particle }\end{array}$} & \multirow{2}{*}{ Steel } & \multicolumn{2}{|c|}{ Corrosion products } & \multirow{2}{*}{$\begin{array}{c}\text { Corrosion rate } \\
(\mathrm{mm} / \mathrm{year})\end{array}$} \\
\hline & & & Steel & Salt & \\
\hline \multirow{3}{*}{$\begin{array}{l}\text { Solar Salt } \\
\text { RSS Grade }\end{array}$} & $\begin{array}{c}\mathrm{Al}_{2} \mathrm{O}_{3} \\
(1 \mathrm{wt} \%)\end{array}$ & 347 & $\begin{array}{c}\mathrm{MgFe}_{2} \mathrm{O}_{4}, \mathrm{Fe}_{2} \mathrm{O}_{3}, \\
\mathrm{Fe}_{3} \mathrm{O}_{4}, \mathrm{Al}_{2} \mathrm{O}_{3}\end{array}$ & $\mathrm{~K}_{2} \mathrm{Fe}_{2} \mathrm{O}_{4}$ & 0.007 \\
\hline & $\begin{array}{c}\mathrm{SiO}_{2} \\
(1 \mathrm{wt} \%)\end{array}$ & 347 & $\begin{array}{c}\mathrm{Fe}_{3} \mathrm{O}_{4}, \mathrm{Fe}_{2} \mathrm{O}_{3}, \\
\mathrm{MgFe}_{2} \mathrm{O}_{4}, \mathrm{KCrO}_{2}\end{array}$ & $\mathrm{MgSiO}_{4}, \mathrm{SiO}_{2}$ & \\
\hline & - & 347 & $\begin{array}{c}\mathrm{MgFe}_{2} \mathrm{O}_{4}, \mathrm{Fe}_{3} \mathrm{O}_{4}, \\
\mathrm{Fe}_{2} \mathrm{O}_{3}\end{array}$ & $\mathrm{Na}_{2} \mathrm{O}$ & 0.021 \\
\hline \multirow{3}{*}{$\begin{array}{l}\text { Solar Salt } \\
\text { ISS Grade }\end{array}$} & $\begin{array}{c}\mathrm{Al}_{2} \mathrm{O}_{3} \\
(1 \mathrm{wt} \%)\end{array}$ & 347 & $\begin{array}{c}\mathrm{MgFe}_{2} \mathrm{O}_{4} \\
\mathrm{MgAl}_{2} \mathrm{O}_{4}, \mathrm{Fe}_{2} \mathrm{O}_{3}\end{array}$ & $\begin{array}{c}\mathrm{Fe}_{3} \mathrm{O}_{4}, \mathrm{Al}_{2} \mathrm{O}_{3} \\
\mathrm{Ca}_{2} \mathrm{Fe}_{2} \mathrm{O}_{5}\end{array}$ & 0.019 \\
\hline & $\begin{array}{c}\mathrm{SiO}_{2} \\
(1 \mathrm{wt} \%)\end{array}$ & 347 & $\begin{array}{c}\mathrm{MgFe}_{2} \mathrm{O}_{4} \\
\mathrm{Fe}_{3} \mathrm{O}_{4}, \mathrm{MgO} \\
\mathrm{SiO}_{2}, \mathrm{Fe}_{2} \mathrm{SiO}_{4}\end{array}$ & $\mathrm{SiO}_{2}, \mathrm{Ca}_{2} \mathrm{Fe}_{2} \mathrm{O}_{5}$ & 0.024 \\
\hline & - & 347 & $\begin{array}{c}\mathrm{MgFe}_{2} \mathrm{O}_{4} \\
\mathrm{Fe}_{3} \mathrm{O}_{4}, \mathrm{MgO}, \\
\mathrm{MgCr}_{2} \mathrm{O}_{4}\end{array}$ & $\begin{array}{c}\mathrm{Fe}_{2} \mathrm{O}_{3} \\
\mathrm{MgFe}_{2} \mathrm{O}_{4}\end{array}$ & 0.027 \\
\hline
\end{tabular}

341

The gravimetric corrosion rate was also included in the table 2. ISS mixture showed the higher corrosion rate due to the higher $\mathrm{Cl}$ content. The effect of nanoparticles does not seem to increase the corrosion rate obtained in the isothermal static study at $565^{\circ} \mathrm{C}$. It has been found that $\mathrm{Al}_{2} \mathrm{O}_{3}$ nanoparticles present a better corrosion protection of the steel matrix when using RSS salts rather than using ISS salts. This effect could be interesting in order to design a protective methodology for the steels in contact with the salt since a superficial Al content has been detected. On the other hand, this corrosion-protective layer formed onto the steel reduces the content of the $\mathrm{Al}_{2} \mathrm{O}_{3}$ nanoparticles in the salt, whose main function is the enhancement of the thermal properties. Corrosion rates are in concordance with the results available in literature, regarding the immersion of 347SS in RSS. Kruizenga [21] reported a weight loss around $1.8 \mathrm{mg} / \mathrm{cm}^{2}$ in same conditions at 1000 hours of test, which correspond to a corrosion rate of $0.02 \mathrm{~mm} / \mathrm{year}$. 


\section{Conclusions}

357 The present work has carried out a corrosion study of a commercial stainless steel (347SS)

358

359

360

361

362

363 into nanofluids made of solar salt doped with $1 \%$ wt. of nanoparticles. The study comprises tests with two different grades of solar salt (refined and industrial) and two different types of nanoparticles, Silica and Alumina.

The results obtained in the corrosion study showed a higher corrosion rate using the industrial solar salt grade, due to the higher chloride content, compared with the other impurity grade (RSS) but the addition of nanoparticles do not increase the corrosion behavior in the storage materials tested.

According with the results obtained, for $\mathrm{RSS}+1 \mathrm{wt} \% \mathrm{Al}_{2} \mathrm{O}_{3}$, a protective layer was obtained. This structure (composed mainly by $\mathrm{Al}_{2} \mathrm{O}_{3}$ ) and integrated in the steel matrix, increase the protection against the corrosion produced by molten salts.

One of the drawbacks detected in the nanofluid was a reduction of the viscosity in the salt during the corrosion test, when $\mathrm{SiO}_{2}$ nanoparticles are involved. In this case, solidification of the salt was produced during the test and the XRD analysis revealed the presence of $\mathrm{SiO}_{2}$ and $\mathrm{MgSiO}_{4}$, as main component in the salt remaining after the corrosion test.

The corrosive evaluation of these nanofluid showed that nanoparticles do not produce an enhancement of the corrosion rate in static conditions. However, the corrosion should also be tested in dynamic conditions since $\mathrm{Al}_{2} \mathrm{O}_{3} / \mathrm{SiO}_{2}$ are solid particles in the mixture, being potential candidates to promote erosion/corrosion in CSP pipelines.

\section{Acknowledgement}

The authors would like to acknowledge the financial support provided by CONICYT / FONDAP 15110019 "Solar Energy Research Center" SERC-Chile. The authors wish to acknowledge the University of the Basque Country UPV/EHU for supporting the PhD of Belén Muñoz-Sánchez (Zabalduz program) and her research stay at the Universidad de Antofagasta. 


\section{References}

1. D. Kearney, B.K., R. Mahoney Assessment of a molten heat transfer fluid in a parabolic trough solar field. Solar Energy Engineering, 2002.

2. Fernandez, A. G., S. Ushak, H. Galleguillos, F.J Perez "Development of new molten salts with LiNO3 and $\mathrm{Ca}(\mathrm{NO} 3) 2$ for energy storage in CSP plants." Applied Energy, 2014, 119: 131-140.

3. Fernandez, A.G., Vidal-Gomez J., Thermophysical properties of low cost lithium nitrate salts produced in northern Chile for thermal energy storage. Renewable Energy, 2016. 101: p. 120-125.

4. Jo, Byeongnam and D. Banerjee, Enhanced specific heat capacity of molten saltbased nanomaterials: Effects of nanoparticle dispersion and solvent material. Acta Materialia, 2014, 75: p. 80-91.

5. Muñoz-Sanchez, B., J. Nieto-Maestre, I. Iparraguirre-Torres, A. García-Romero, J.M. Sala-Lizarraga, Molten salt-based nanofluids as efficient heat transfer and storage materials at high temperatures. An overview of the literature. Renewable and Sustainable Energy Reviews. 2017, 82: p. 3924-3945.

6. Ho, M.X. and C. Pan, Optimal concentration of alumina nanoparticles in molten Hitec salt to maximize its specific heat capacity. International Journal of Heat and Mass Transfer, 2014, 70(0): p. 174-184.

7. Ho, M.X. and C. Pan, Experimental investigation of heat transfer performance of molten HITEC salt flow with alumina nanoparticles. International Journal of Heat and Mass Transfer, 2017, 107: p. 1094-1103.

8. Alashkar, A. and M. Gadalla, Thermo-economic analysis of an integrated solar power generation system using nanofluids. Applied Energy, 2017, 191: p. 469491.

9. Madathil, P.K., Preparation and characterization of molten salt based nanothermic fluids with enhanced thermal properties for solar thermal applications. Applied Thermal Engineering, 2016, 109: p. 901-905.

10. Tian, H., Enhanced Specific Heat of Chloride Salt with Mg Particles for Hightemperature Thermal Energy Storage. Energy Procedia, 2017, 105: p. 4402-4407.

11. D. Shin, D.B., Enhanced specific heat of silica nanofluid. J. Heat Transfer, 2011. 133: p. 024501.

12. D. Shin, D.B., Enhanced specific heat capacity of nanomaterials synthesized by dispersing silica nanoparticles in eutectic mixtures. J. Heat Transfer 2013. 135: p. 032801.

13. Gasia, J., L. Miro, and L.F. Cabeza, Review on system and materials requirements for high temperature thermal energy storage. Part 1: General requirements. Renewable and Sustainable Energy Reviews, 2017, 75: p. 1320-1338.

14. Kruizenga, A.M., Corrosion Mechanisms in Chloride and Carbonate Salts. Sandia Report, 2012. SAND2012-7594.

15. Fernandez, A.G., M. Grageda, and H. Galleguillos, Impurity Influence in Physicochemical and Corrosion Properties of Chilean Solar Nitrates. Energy Procedia, 2014, 49: p. 607-616.

16. Fernandez, A.G., H. Galleguillos, and F.J. Perez, Thermal influence in corrosion properties of Chilean solar nitrates. Solar Energy, 2014, 109(0): p. 125-134.

17. Groll, M., O. Brost, and D. Heine, Corrosion of steels in contact with salt eutectics as latent heat storage materials: Influence of water and other impurities. Heat Recovery Systems and CHP, 1990. 10(5-6): p. 567-572. 
18. Muñoz-Sanchez, B., J. Nieto-Maestre, A precise method to measure the specific heat of solar salt-based nanofluids. Journal of Thermal Analysis and Calorimetry, 2017. 192(2): p. 905-914.

19. Abdel Hamid, Z., S. Abd El Rehim, Effectiveness of Si contents in the steel composition on the corrosion performance of galvanized steel. Anti-Corrosion Methods and Materials, 2017. 65(5): p. 479-485.

20. Yang, C., NOx emissions and the component changes of ternary molten nitrate salts in thermal energy storage process. Applied Energy, 2016, 184: p. 346-352.

21. A.M. Kruizenga, D.D.G., M. LaFord, Materials Corrosion of High Temperature Alloys Immersed in $600{ }^{\circ} \mathrm{C}$ Binary Nitrate Salt. SAND2013-2526., 2013. 
Highlights:

Corrosion rates obtained during the experiments are similar using nanosalts or conventional nitrate molten salts.

The knowledge acquired in corrosion using nanosalts can help to understand the corrosion issues associated with doped molten salts under operation in CSP plants.

$>$ The use of molten salts doped with $\mathrm{Al}_{2} \mathrm{O}_{3}$ nanoparticles could increase the corrosion resistance in steels in contact with them 